\title{
Biometrical genetical analysis of tetrasomic inheritance based on matings of diploid parents which produce 2 n gametes
}

\author{
G. C. C. Tai
}

Agriculture Canada Research Station, P.O. Box 20280, Fredericton, N.B., E3B 4Z7, Canada.

This paper describes a mating scheme for estimating genetic parameters in an additive-dominance model for autotetraploids. The two parents used in the scheme are homozygous diploids which produce $2 \mathrm{n}$ unreduced gametes. The estimation procedure uses means of autotetraploids of the two parents, their $F_{1}$ and eight backcross generations.

\section{INTRODUCTION}

Haploids can now be induced either in vitro (e.g., anther culture) or in vivo (e.g., pseudogamy) in many crop species (Hermsen and Ramanna, 1981). Haploids (2X) extracted from autotetraploid (4X) species, notably alfalfa and potato, can be used to cross with related diploid (2X) species. More importantly, these $2 \mathrm{X}$ plants may produce $2 \mathrm{n}$ unreduced gametes. Thus, they can be used in tetraploid-diploid (4X-2X) matings for maximising heterozygosity in autotetraploids (Mendiburu, Peloquin and Mok, 1974; Bingham, 1979; 1983). The $2 n$ gametes are produced by either first (FDR) or second (SDR) division restitution during meiosis (Mendiburu and Peloquin, 1979). These two mechanisms of 2 -gamete formation have been found useful in gene-centromere mapping based on $4 \mathrm{X}-2 \mathrm{X}$ matings in potatoes (Mendiburu and Peloquin, 1979). Tai $(1982 a ; b)$ proposed two mating schemes, each of which involves a series of $4 X-2 X, 4 X-4 X$ and/or $2 X-2 X$ matings, for estimating double reduction and genetic parameters of autotetraploids. The present study attempts to propose another mating system which is strictly based on FDR or SDR diploid parents for biometrical genetical analysis of tetrasomic inheritance.

\section{Frequencies of $4 X$ genotypes in progenies of matings between diploids}

We assume that two homozygous diploids are available. They are capable of producing both $n$ and $2 \mathrm{n}$ gametes. One of them, say AA, can produce a reasonable proportion of both $2 n$ pollen and $2 n$ eggs. Another one, aa, produces $2 n$ eggs (or pollen). Mating between AA and aa would produce both diploid ( $\mathrm{Aa}$ ) and tetraploid (AAaa) $\mathrm{F}_{1}$ progenies. It is expected the $F_{1}(A a)$ is again capable of producing $2 n$ pollen (or eggs) by FDR or SDR during meiosis. We shall consider the case of FDR. The principle of using SDR diploids is exactly the same as the FDR's.

The diploid $F_{1}(\mathrm{Aa})$ produces $n$ gametes of $A$ and a with the ratio $1: 1$. The same genotype produces $2 \mathrm{n}$ gametes of $\mathrm{AA}, \mathrm{Aa}$ and aa with relative frequencies $\beta / 4: 1-\beta / 2: \beta / 4$ based on the FDR mechanism. The coefficient $\beta$ is the frequency of single exchange tetrads (Mendiburu and Peloquin, 1979). The diploid $F_{1}(\mathrm{Aa})$ plants are then selfed and backcrossed to both parents (AA and aa) to produce diploid $F_{2}$ and backcross families. All diploid families are again expected to produce both $\mathrm{n}$ and $2 \mathrm{n}$ gametes. Table 1 presents the relative frequencies of different genotypes in $n$ and $2 n$ gametes produced by these families.

Frequencies of $4 \mathrm{X}$ genotypes in progenies of these families and crosses between them can be worked out using information in table 1 . Table 2 gives results of 11 families. These families are involved in our proposed mating scheme for estimating genetic parameters.

\section{Estimation of genetic parameters}

The following mating scheme is proposed for estimating genetic parameters involved in 
Table 1 Frequencies of different genotypes in $n$ and $2 n$ gametes produced by different types of diploid families

\begin{tabular}{lcclll}
\hline & \multicolumn{3}{c}{ n gamete } & \multicolumn{3}{c}{ 2n gamete } \\
Family & A & a & AA & Aa & aa \\
\hline AA & 1 & 0 & 1 & 0 & 0 \\
aa & 0 & 1 & 0 & 0 & 1 \\
$\mathrm{Aa}$ & 1 & 1 & $\beta / 4$ & $1-\beta / 2$ & $\beta / 4$ \\
$\mathrm{AA} \times \mathrm{Aa}$ & $\frac{3}{4}$ & $\frac{1}{4}$ & $\frac{1}{2}+\beta / 8$ & $\frac{1}{2}-\beta / 4$ & $\beta / 8$ \\
$\mathrm{aa} \times \mathrm{Aa}$ & $\frac{1}{4}$ & $\frac{3}{4}$ & $\beta / 8$ & $\frac{1}{2}-\beta / 4$ & $\frac{1}{2}+\beta / 8$ \\
$\mathrm{Aa} \times \mathrm{Aa}$ & 1 & 1 & $\frac{1}{4}+\beta / 8$ & $\frac{1}{2}-\beta / 8$ & $\frac{1}{4}+\beta / 8$ \\
\hline
\end{tabular}

tetrasomic inheritance:

$\begin{array}{lll}\text { Type of cross } & \text { Mating scheme } & \text { Symbols } \\ 2 \mathrm{X} * 2 \mathrm{X} & \mathrm{AA} \times \mathrm{aa} & \mathrm{F}_{1} \\ 2 \mathrm{X} * 2 \mathrm{X} & \mathrm{AA} \times \mathrm{Aa} & \mathrm{B}_{1} \\ 2 \mathrm{X} * 2 \mathrm{X} & \mathrm{a} \times \mathrm{Aa} & \mathrm{B}_{2} \\ 2 \mathrm{X} * 2 \mathrm{X} & \mathrm{AA} \times(\mathrm{AA} \times \mathrm{Aa}) & \mathrm{B}_{11} \\ 2 \mathrm{X} * 2 \mathrm{X} & \mathrm{AA} \times(\mathrm{aa} \times \mathrm{Aa}) & \mathrm{B}_{12} \\ 2 \mathrm{X} * 2 \mathrm{X} & \mathrm{a} \times(\mathrm{AA} \times \mathrm{Aa}) & \mathrm{B}_{21} \\ 2 \mathrm{X} * 2 \mathrm{X} & \mathrm{a} \times(\mathrm{aa} \times \mathrm{Aa}) & \mathrm{B}_{22} \\ 2 \mathrm{X} * 2 \mathrm{X} & \mathrm{AA} \times(\mathrm{Aa} \times \mathrm{Aa}) & \mathrm{B}_{13} \\ 2 \mathrm{X} * 2 \mathrm{X} & \mathrm{a} \times(\mathrm{Aa} \times \mathrm{Aa}) & \mathrm{B}_{23}\end{array}$

A unique feature of the above scheme is that all matings are of $2 \mathrm{X} * 2 \mathrm{X}$ type of crosses. For example, $\mathrm{AA} \times(\mathrm{AA} \times \mathrm{Aa})$ represents the mating of $2 \mathrm{X}$ progenies of the cross $\mathrm{AA} \times \mathrm{Aa}$ with $2 \mathrm{X}$ parent AA. It is also noted at least one parent of each of the matings is homozygous, i.e., AA or aa. Tetraploid progenies are extracted from the nine families. Together with the tetraploids of two parents, i.e., AAAA and aaaa, they can be tested in an experiment. The means of the 11 families can then be used in a weighted least square procedure similar to the one described by Tai $(1982 b)$ for estimating various genetic parameters according to the additive-dominance model of Mather and Jinks (1982) and Killick (1971). Let $m$ be the mid-homozygous value, and $d, h_{3}, h_{2}, h_{1}$ and $-d$, the mean phenotypic deviations from $m$ for
AAAA, AAAa, AAaa, Aaaa and aaaa genotypes, respectively. The expected means of two parental tetraploids $P_{1}$ and $P_{2}$, and $F_{1}, B_{1}, B_{2}, B_{11}, B_{12}$, $B_{21}, B_{22}, B_{13}$, and $B_{23}$ can be derived based on information in table 2. They are as follows:

$$
\begin{aligned}
\overline{\mathrm{P}}_{1}= & m+d \\
\overline{\mathrm{P}}_{2}= & m-d \\
\overline{\mathrm{F}}_{1}= & m+h_{2} \\
\overline{\mathrm{B}}_{1}= & m+\beta / 4\left(d+h_{2}\right)+(1-\beta / 2) h_{3} \\
= & m+h_{3}^{\prime} \\
\overline{\mathrm{B}}_{2}= & m-\beta / 4\left(d-h_{2}\right)+(1-\beta / 2) h_{1} \\
= & m+h_{1}^{\prime} \\
\overline{\mathrm{B}}_{11}= & m+1 / 2 d+\beta / 8\left(d+h_{2}\right)+1 / 2(1-\beta / 2) h_{3} \\
= & m+1 / 2 d+1 / 2 h_{3}^{\prime} \\
\overline{\mathrm{B}}_{12}= & m+1 / 2 h_{2}-\beta / 8\left(d+h_{2}\right)+1 / 2(1-\beta / 2) h_{3} \\
= & m+1 / 2 h_{2}+1 / 2 h_{3}^{\prime} \\
\overline{\mathrm{B}}_{21}= & m+1 / 2 h_{2}-\beta / 8\left(d-h_{2}\right)+1 / 2(1-\beta / 2) h_{1} \\
= & m+1 / 2 h_{2}+1 / 2 h_{1}^{\prime} \\
\overline{\mathrm{B}}_{22}= & m+1 / 2 d-\beta / 8\left(d-h_{2}\right)+1 / 2(1-\beta / 2) h_{1} \\
= & m-1 / 2 d+1 / 2 h_{1}^{\prime} \\
\overrightarrow{\mathrm{B}}_{13}= & m+1 / 4 d+1 / 4 h_{2}+\beta / 8\left(d+h_{2}\right) \\
& +1 / 2(1-\beta / 2) h_{3} \\
= & m+1 / 4 d+1 / 4 h_{2}+1 / 2 h_{3}^{\prime} \\
\overrightarrow{\mathrm{B}}_{23}= & m-1 / 4 d+1 / 4 h_{2}-\beta / 8\left(d-h_{2}\right) \\
& +1 / 2(1-\beta / 2) h_{1} \\
= & m-1 / 4 d+1 / 4 h_{2}+1 / 2 h_{1}^{\prime}
\end{aligned}
$$

\begin{tabular}{|c|c|c|c|c|c|c|}
\hline \multirow[b]{2}{*}{ Family } & \multirow[b]{2}{*}{ Symbol } & \multirow[b]{2}{*}{ AAAA } & \multicolumn{2}{|c|}{$4 \mathrm{X}$ genotypes } & \multirow[b]{2}{*}{ Aaaa } & \multirow[b]{2}{*}{ aаaa } \\
\hline & & & AAAa & AAaa & & \\
\hline $\mathrm{AA}$ & $P_{1}$ & 1 & 0 & 0 & 0 & 0 \\
\hline aa & $\mathrm{P}_{2}$ & 0 & 0 & 0 & 0 & 1 \\
\hline $\mathrm{Aa}$ & $F_{1}$ & 0 & 0 & 1 & 0 & 0 \\
\hline $\mathbf{A A} \times \mathbf{A a}$ & $\mathrm{B}_{1}$ & $\beta / 4$ & $1-\beta / 4$ & $1-\beta / 4$ & 0 & 0 \\
\hline $\mathrm{aa} \times \mathrm{Aa}$ & $\mathbf{B}_{2}$ & 0 & 0 & $\beta / 4$ & $1-\beta / 4$ & $\beta / 4$ \\
\hline $\mathbf{A} \mathbf{A} \times(\mathbf{A} \mathbf{A} \times \mathbf{A a})$ & $\mathbf{B}_{11}$ & $\frac{1}{2}+\beta / 8$ & $\frac{1}{2}-\beta / 4$ & $\beta / 8$ & 0 & 0 \\
\hline $\mathbf{A A} \times(\mathbf{a} \mathbf{a} \times \mathbf{A a})$ & $\mathbf{B}_{12}$ & $\beta / 8$ & $\frac{1}{2}-\beta / 4$ & $\frac{1}{2}+\beta / 8$ & 0 & 0 \\
\hline $\mathbf{a} \mathbf{a} \times(\mathbf{A} \mathbf{A} \times \mathbf{A a})$ & $\mathbf{B}_{21}$ & 0 & 0 & $\frac{1}{2}+\beta / 8$ & $\frac{1}{2}-\beta / 4$ & $\beta / 8$ \\
\hline $\mathrm{a} a \dot{a} \times(\mathrm{aa} \times \mathrm{Aa})$ & $\mathbf{B}_{22}$ & 0 & 0 & $\beta / 8$ & $\frac{1}{2}-\beta / 4$ & $\frac{1}{2}+\beta / 8$ \\
\hline $\mathbf{A A} \times(\mathbf{A a} \times \mathbf{A a})$ & $\mathbf{B}_{13}$ & $\frac{1}{4}+\beta / 8$ & $\frac{1}{2}-\beta / 4$ & $\frac{1}{4}+\beta / 8$ & 0 & 0 \\
\hline $\mathrm{aa} \times(\mathrm{Aa} \times \mathrm{Aa})$ & $\mathrm{B}_{23}$ & 0 & 0 & $\frac{1}{4}+\beta / 8$ & $\frac{1}{2}-\beta / 4$ & $\frac{1}{4}+\beta / 8$ \\
\hline
\end{tabular}

where $\quad h_{3}^{\prime}=h_{3}+\beta / 4\left(d+h_{2}-2 h_{3}\right)$ and $h_{1}^{\prime}=$ $h_{1}-\beta / 4\left(d-h_{2}+2 h_{1}\right)$. These equations are solved

Table 2 Frequencies of $4 X$ genotypes in the progenies of 11 diploid families 
for $m, d, h_{2}, h_{3}^{\prime}$, and $h_{1}^{\prime}$. It is noted $h_{3}^{\prime}$ and $h_{1}^{\prime}$, instead of $h_{3}$ and $h_{1}$, are estimated. They represent biased estimates of $h_{3}$ and $h_{1}$ when $\beta>0$. There are 11 means for estimating 5 genetic parameters. This leaves 6 degrees of freedom for a Chi-square test for the adequacy of their additive-dominance model.

\section{DISCUSSION}

The proposed mating scheme uses tetraploids of two homozygous parents, their $F_{1}$, and progenies of eight backcross generations for experimental purpose. It does not intend to use tetraploid progenies of either $F_{2}$ and selfed families in later generations or bipaiental families between hybrid progenies. Tetraploids from these families would be produced by heterozygous genotypes. There is, at the moment, no assurance that $2 \mathrm{n}$ pollen and eggs of a specific parent are formed by the same restitutional mechanism. Thus, they are excluded in the mating scheme. Another distinct feature of the present scheme is that all matings are of $2 \mathrm{x} * 2 \mathrm{x}$ type of crosses. The double-reduction coefficient, $\alpha$, is consequently not involved in the estimation of genetic parameters.

The eight backcross generations involved in the mating scheme provide more than the minimum number of family means required for estimating 5 genetic parameters. The aim of presenting the parametric structure of all of them is to demonstrate that the trisomic effect $h_{3}$ and monosomic effect $h_{1}$ have to be estimated with a multiplicative term involving $\beta$, which is related to the distance of a gene from the centromere, and the parameters $d$, $h_{2}$, and $h_{3}$ or $h_{1}$. The 2 parameters $h_{3}^{\prime}$ and $h_{1}^{\prime}$ represent unbiased estimates of $h_{3}$ and $h_{1}$ only when $\beta=0$, i.e., the situation of chromosomal segregation. The remarkable fact is, however, that $h_{3}^{\prime}$ and $h_{1}^{\prime}$ are integral components in the expressions of all backcross generations in the mating scheme. Thus, the distance of a gene from the centromere of a chromosome has a definite bearing on the expression of genic interactions in tetrasomic inheritance. The two quantities $\beta / 4$ $\left(d+h_{2}-2 h_{3}\right)$ and $\beta / 4\left(d-h_{2}+2 h_{1}\right)$ in $h_{3}^{\prime}$ and $h_{1}^{\prime}$ respectively can be regarded as measuring "position effects" of polygenes on quantitatively inherited traits.

Data obtained from the present mating scheme cannot provide an estimate of $\beta$. Hence $h_{3}$ and $h_{1}$ as well as the position effects cannot be independently estimated. To achieve such a purpose tetraploid progenies from $F_{2}$ or other crosses from heterozygous parents (e.g., $\mathrm{Aa} \times(\mathrm{Aa} \times \mathrm{Aa}))$ will have to be used in the mating design. In this case, the mechanism of $2 \mathrm{n}$ gamete formation should be proven identical in all male and female diploid parents.

Diploid families can be obtained from the same mating scheme. A concurrent experiment involving both diploid and tetraploid families would enable one to compare genetical behaviour of polygenic traits at two ploidy levels. The means of six backcross generations $\left(B_{1}, B_{2}, B_{11}, B_{12}, B_{21}\right.$ and $\left.B_{22}\right)$ bear simple relationships with those of $P_{1}, P_{2}$ and $F_{1}$ in the diploid population under an additivedominance model (see table 12, Mather and Jinks, 1982). These relationships do not exist in the tetraploid population. The following relationships, interestingly, hold true at both ploidy levels:

$$
\begin{aligned}
& 2 \overline{\mathrm{B}}_{11}+2 \overline{\mathrm{B}}_{22}-\overline{\mathrm{B}}_{1}-\overline{\mathrm{B}}_{2}=\overline{\mathrm{P}}_{1}+\overline{\mathrm{P}}_{2} \\
& 2 \overline{\mathrm{B}}_{11}+2 \overline{\mathrm{B}}_{12}-2 \overline{\mathrm{B}}_{21}-2 \overline{\mathrm{B}}_{22}=\overline{\mathrm{P}}_{1}-\overline{\mathrm{P}}_{2} \\
& 2 \overline{\mathrm{B}}_{21}+2 \overline{\mathrm{B}}_{12}-\overline{\mathrm{B}}_{1}-\overline{\mathrm{B}}_{2}=2 \overline{\mathrm{F}}_{1}
\end{aligned}
$$

These relationships can be used for simultaneous scaling test for the adequacy of additive-dominance model at both ploidy levels.

Acknowledgement The author wishes to thank Dr H. S. Pooni for his critical review of the manuscript. He is also indebted to the referee for comments which led to improvement of the paper.

\section{REFERENCES}

BINGHAM, E. T. 1979. Maximizing heterozygosity in autotetraploids. Lewis, W. H. (ed.), In Polyploidy: biological relevance, Plenum Press, New York, pp. 471-489.

BINGHAM, E. T. 1983. Maximizing hybrid vigour in autotetraploid alfalfa. Nugert, J. and O'Conner, M. (eds.), In Better crops of potatoes, Ciba Foundation Symposium 97. Pitman, London, pp. 130 143.

HERMSEN, J. G. T. AND RAMANNA, M. S. 1981. Haploidy and plant breeding. Phil. Trans. R. Soc. Lond., B 292, 499-507.

KILLICK, R. J. 1971. The biometrical genetics of autotetraploids. 1. Generations derived from a cross between two pure lines. Heredity, 27, 331-346.

MATHER, K. AND JINKS, J. L. 1982. Biometrical Genetics. Third edition. Chapman Hall, London.

MENDIBURU, A. O. AND PEloQUiN, S. J. 1979. Genecentromere mapping by $4 \mathrm{X}-2 \mathrm{X}$ mating in potatoes. Theor. Appl. Genet., 54, 177-180.

MENDIBURU, A. O., PELOQUiN, S. J. AND MOK, D. W. S. 1974. Potato breeding with haploids and $2 \mathrm{n}$ gametes. Kasha, $\mathrm{K}$. J. (ed.), In Haploids in higher plants. Advances and potential, Univ. of Guelph, Ont., pp. 249-259.

TAI, G. C. C. $1982 a$. Estimation of double reduction and genetic parameters of autotetraploids. Heredity, 49, 63-70.

TAI, G. C. C. 1982 b. Estimation of double reduction and genetic parameters in autotetraploids based on $4 X-2 X$ and $4 X-4 X$ matings. Heredity, 49, 333-357. 